\title{
PERBANDINGAN ANTARA JOGING DENGAN MENDENGARKAN MUSIK DAN JOGING TANPA MENDENGARKAN MUSIK TERHADAP JARAK TEMPUH
}

\author{
Adika Fatahilah', Wawan Syafutra ${ }^{2}$ \\ STKIP PGRI Lubuklinggau \\ fatahilah.adika@yahoo.co.id
}

\begin{abstract}
Abstrak
Permasalahan utama dalam penelitian ini performa jogging dapat dilihat dari seberapa jauh jarak tempuh yang didapatkan oleh individu. Rasa bosan, tidak nyaman, tertekan, dan rasa capek dapat membuat individu kurang mencurahkan perhatiannya secara penuh pada kegiatan jogging. Hal ini menandakan bahwa dirinya merasa tidak enjoy. Tujuan dari penelitian ini adalah Untuk mengetahui perbandingan anatara joging dengan menggunakan musik dan joging tanpa menggunakan musik terhadap jarak tempuh joging pada mahasiswa PJKR STKIP PGRI Lubuklinggau. Penelitian ini menggunakan metode eksperiment semu. Populasi pada penelitian ini adalah mahasiswa PJKR STKIP PGRI Lubuklinggau angkatan 2017 Kelas A,B,C. sampel ditetapkan secara purposive sampling, hanya diambil mahasiswa laki-laki dengan jumlah 15 orang dan perempuan berjumlah 15 orang. Teknik analisis data yang digunakan adalah teknik analisis deskriptif dan infersial dengan menggunakan program SPSS Versi 22.00 pada taraf signifikan $95 \%$ atau $\alpha 0,05$. Hasil penelitian menyimpulkan bahwa: Berdasarkan tsbel output Pairec Sampel Test, diketahui nilai Sig. (2-tailed) adalah sebesar 0,008 < 0,05, maka $\mathrm{H}_{0}$ ditolak dan Ha diterima. Sehingga dapat disimpulkan bahwa ada perbedaan rata-rata antara Tes Joging Pre Test (tidak mendengarkan musik) dengan Post Test (mendengarkan musik) yang artinya ada perbandingan penggunaan musik saat joging dan tidak menggunakan musik saat joging terhadap hasil jarak tempuh joging.
\end{abstract}

Kata Kunci : Joging, Musik, Jarak tempuh.

\begin{abstract}
The main problem in this study the performance of jogging can be seen from the distance traveled obtained by individuals. Feeling bored, uncomfortable, depressed, and tired can make people pay less attention to jogging activities. Enjoy. The purpose of this study was to study the anatomy of jogging using music and jogging without using music for jogging distance in PJKR STKIP PGRI Lubuklinggau students. This study uses quasi-experimental methods. The population in this study were PJKR STKIP PGRI Lubuklinggau students Class A, B, C year 2017. The sample was determined by purposive sampling, only 15 male students were taken and 15 female students were taken. The data analysis technique used is descriptive and commercial analysis techniques using the SPSS Version 22.00 program at a significant level of $95 \%$ or $\alpha 0.05$. The results of the study concluded that: Based on the results of the Pairec Sample Test, the Sig value was recognized. (2-tailed) is $0.008<0.05$, then HO is rejected and Ha is accepted. Scales of Jogging Trials (not listening to music) with a Post Test (listening to music) that discusses the use of music when jogging and not using music when jogging to produce jogging mileage.
\end{abstract}

Key Words: Jogging, Music, Mileage.

Dipublikasikan Oleh :

UPT Publikasi dan Pengelolaan Jurnal

Universitas Islam Kalimantan Muhammad Arsyad Al-Banjari Banjarmasin 


\section{PENDAHULUAN}

Dalam kehidupan sehari-hari, dapat dipastikan bahwa semua manusia setidaknya melakukan satu jenis aktivitas fisik. Mendorong kereta bayi, menaiki anak tangga, mencuci piring, berjalan, berkebun, atau bermain sepak bola merupakan beberapa contoh dari aktivitas fisik. Menurut Corbin \& Lindsey (1997), aktivitas fisik mengacu pada istilah umum yang digunakan untuk menjelaskan segala bentuk aktivitas yang menggerakkan otot dalam skala besar, seperti berolahraga, berdansa, bermain, dan bekerja. Agar manusia dapat menjalankan kehidupannya dengan lebih optimal, mereka membutuhkan tubuh yang sehat dan bugar. Hal ini dapat dicapai dengan melakukan aktivitas fisik berupa olahraga. Seperti yang kita ketahui, olahraga memberikan banyak sekali manfaat untuk manusia.

Dari sekian banyak jenis olahraga, jogging merupakan olahraga yang cukup banyak dipilih oleh orang-orang. Alasannya karena jogging dapat dilakukan kapan saja dan dimana saja. Jogging dapat dilakukan pada pagi hari, siang hari, atau sore hari. Jogging dapat dilakukan di sekitar komplek rumah, area kampus, ataupun gelanggang olahraga (GOR). Walaupun jogging dapat dikatakan sebagai olahraga yang mudah untuk dilakukan, tidak semua orang dapat menikmatinya dengan baik. Masalah yang sering ditemui dalam kegiatan ini adalah rasa bosan, tidak nyaman, tertekan, dan rasa capek, yang berdampak pada kualitas performa jogging individu. Menurut Chaplin (1995), performa adalah tingkah laku yang membuahkan satu hasil, khususnya tingkah laku yang dapat mengubah lingkungan dengan cara-cara tertentu.

Performa jogging dapat dilihat dari seberapa jauh jarak tempuh yang didapatkan oleh individu. Kunci performa yang optimal adalah konsentrasi. Konsentrasi disini maksudnya mencurahkan perhatian secara penuh pada kegiatan yang dilakukan. Rasa bosan, tidak nyaman, tertekan, dan rasa capek dapat membuat individu kurang mencurahkan perhatiannya secara penuh pada kegiatan jogging. Hal ini menandakan bahwa dirinya merasa tidak enjoy. Menurut Motl, Dishman, Sounders, Dowda, Felton, dan Pate (2001) dalam Weng (2006), enjoyment adalah keadaan afektif yang positif, mencerminkan perasaan seperti fun dan pleasure. Tidak enjoy-nya individu menjadi tanda bahwa motivasi intrinsik belum terbentuk pada dirinya. Padahal, ketika individu termotivasi secara intrinsik untuk melakukan suatu kegiatan, berarti kegiatan tersebut memang menarik dan menyenangkan. Ia akan menjadi benar-benar mencurahkan perhatiannya pada kegiatan itu dan mungkin akan mengalami flow serta akan merasa ,,lupa waktu ${ }^{e e}$. (Csikszentmihalyi, 1975 dalam Deci \& Ryan, 1985).

Sebenarnya, rasa tidak enjoy tersebut dapat diatasi salah satunya dengan mendengarkan musik melalui personal stereo. Personal stereo yang merupakan alat pemutar musik portable ini berfungsi untuk menahan segala suara eksternal yang tidak diinginkan. Selain itu juga berfungsi untuk membentuk mood dan menstabilkan emosi melalui musik yang ,tepat" dan „sesuaie dengan mood dan lingkungan (Bull, 2000 dalam Weng, 2006). Musik yang „tepate dan „sesuaie akan berbeda pada setiap individu. Oleh karena itu, jenis musik yang didengarkan sebaiknya adalah musik yang dipilih dan disenangi oleh individu (self-preferred music).

Menurut Stratton \& Zalanowski (1984) dalam Weng (2006), self-preferred music memang penting dalam membuat individu menjadi rileks. Hal ini terjadi karena musik memiliki tiga efek dalam berolahraga, yaitu efek psikologis, psikofisik, dan peningkatan performa (Karageorghis \& Terry, 1997 dalam Bateman \& Bale, 2009). Musik secara statistik juga memiliki efek yang signifikan terhadap olahraga aerobik, dimana partisipan yang berolahraga dengan mendengarkan musik berjalan lebih jauh dan dengan tenaga yang lebih sedikit dibandingkan partisipan yang berolahraga tanpa menggunakan musik (Beckett, 1990 dalam Weng, 2006). Hasil yang serupa juga didapat dalam penelitian Boldt (1996) dalam Weng (2006), dimana musik membantu meningkatkan daya tahan untuk berolahraga dalam jangka waktu yang lama dan meningkatkan level selfreported relaxation. Dalam hasil penelitian yang melihat hubungan antara musik dan olahraga (Karageorghis \& Terry, 1997 dalam Weng, 2006), dikatakan bahwa motivational music mampu menstimulasi individu untuk mencapai intensitas olahraga sub-maximal dimana individu tidak merasa terkurasnya banyak energi. Selain itu, terdapat peningkatan level kondisi positive affective selama berolahraga.

Hal ini menunjukkan bahwa musik, terutama self-preferred music berpengaruh pada performa olahraga individu, dengan cara meningkatkan motivasi intrinsik melalui peningkatan enjoyment individu. Seperti yang telah dijelaskan diatas bahwa musik memiliki banyak manfaat terhadap kegiatan olahraga. 


\section{METODE}

Penelitian ini menggunakan metode eksperiment semu, data masing-masing variabel akan dipaparkan secara deskriptif. Populasi pada penelitian ini adalah mahasiswa PJKR STKIP PGRI Lubuklinggau angkatan 2017 Kelas A,B,C. sampel ditetapkan secara purposive sampling, "teknik ini digunakan apabila anggota sampel yang dipilih secara khusus berdasarkan tujuan penelitian. Berpedoman pada tabel populasi diatas, maka penelitian ini hanya diambil mahasiswa laki-laki dengan jumlah 15 orang dan perempuan berjumlah 15 orang. Penelitian ini dilaksanakan kurang lebih dua bulan. Penelitian ini akan dilaksanakan di Stadion Taman Olahraga Silampari.

Teknik pengambilan data Data yang dibutuhkan dalam penelitian ini adalah data primer yaitu data yang diambil langsung dari hasil tes Jogging menggunakan musik dan joging tanpa menggunakan musik. Dimana sampel melakukan joging selama 30 menit dan seberapa jauh jarak tempuh yang di ukur.

Analisis data yang di gunakan dalam penelitian ini adalah analisis inferensial dilakukan untuk menguji hipotesis yang diajukan dengan menggunakan Teknik analisis data yang digunakan untuk pengujian hipotesis dalam penelitian ini adalah menggunakan rumus t-tes sebagai berikut :

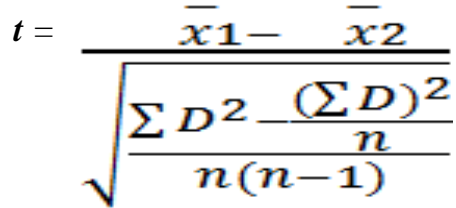

keterangan :

$$
\begin{gathered}
x 1=\text { Mean sampel pertama } \\
-\quad=\text { Mean sampel kedua } \\
x 2=\text { Beda antara skor pertama dan kedua } \\
D=\text { Kuadrat beda } \\
D^{2}=\text { Jumlah kuadrat beda } \\
\sum D^{2}=\text { Jumlah sampel } \\
N=\text { - } 1
\end{gathered}
$$

\section{HASIL DAN PEMBAHASAN}

Deskripsi data yang akan disajikan berupa data hasil tes Jogging menggunakan musik dan joging tanpa menggunakan musik.

\section{Tabel 5. Hasil Tes}

\begin{tabular}{|c|c|c|c|}
\hline \multicolumn{2}{|c|}{ TES JOGING } & \multirow{2}{*}{ KODE A } & \multirow{2}{*}{ KODE B } \\
\cline { 1 - 2 } $\begin{array}{c}\text { Tidak Mendengarkan } \\
\text { Musik }\end{array}$ & $\begin{array}{c}\text { Mendengarkan } \\
\text { Musik }\end{array}$ & 1 & 2 \\
\hline 5000 & 5200 & 1 & 2 \\
\hline 6300 & 5000 & 1 & 2 \\
\hline 5500 & 5600 & 1 & 2 \\
\hline 5600 & 5000 & 1 & 2 \\
\hline 5000 & 5200 & 1 & 2 \\
\hline 6900 & 6500 & 1 & 2 \\
\hline 5800 & 5300 & 1 & 2 \\
\hline 5500 & 6400 & 1 & 2 \\
\hline 6800 & 7200 & 1 & 2 \\
\hline 5600 & 5000 & 1 & 2 \\
\hline 5400 & 6500 & 1 & 2 \\
\hline 6700 & 5000 & 1 & 2 \\
\hline 5000 & 6300 & & \\
\hline
\end{tabular}

Dipublikasikan Oleh :

UPT Publikasi dan Pengelolaan Jurnal

Universitas Islam Kalimantan Muhammad Arsyad Al-Banjari Banjarmasin 


\begin{tabular}{|c|c|c|c|}
\hline 5300 & 5400 & 1 & 2 \\
\hline 7000 & 7800 & 1 & 2 \\
\hline 6800 & 6200 & 1 & 2 \\
\hline 6500 & 7300 & 1 & 2 \\
\hline 7500 & 7500 & 1 & 2 \\
\hline 7300 & 8000 & 1 & 2 \\
\hline 7600 & 6800 & 1 & 2 \\
\hline 7000 & 7000 & 1 & 2 \\
\hline 7300 & 7500 & 1 & 2 \\
\hline 8000 & 8500 & 1 & 2 \\
\hline 7000 & 7500 & 1 & 2 \\
\hline 8200 & 8500 & 1 & 2 \\
\hline 6800 & 6900 & 1 & 2 \\
\hline 7600 & 8200 & 1 & 2 \\
\hline 6600 & 7000 & 1 & 2 \\
\hline 7300 & 8500 & 1 & 2 \\
\hline 5000 & 5200 & 1 & \\
\hline
\end{tabular}

\begin{tabular}{|ll|r|r|}
\hline \multicolumn{3}{|c|}{ One-Sample Kolmogorov-Smirnov Test } \\
\hline \multicolumn{1}{|c|}{} & $\begin{array}{r}\text { TIDAK } \\
\text { MENDENGAR } \\
\text { KAN MUSIK }\end{array}$ & $\begin{array}{r}\text { MENDENGAR } \\
\text { KAN MUSIK }\end{array}$ \\
\hline $\mathrm{N}$ & & 30 & 30 \\
Normal Parameters & & \\
& Mean & 6463,33 & 6600,00 \\
Most Extreme Differences & Std. Deviation & 973,257 & 1190,190 \\
& Absolute &, 146 &, 143 \\
& Positive &, 146 &, 143 \\
Test Statistic & Negative &,- 135 &,- 089 \\
Asymp. Sig. (2-tailed) & &, 146 &, 143 \\
\hline
\end{tabular}
a. Test distribution is Normal.
b. Calculated from data.
c. Lilliefors Significance Correction.

Hasil uji normalitas yang digambarkan pada tabel diatas menunjukkan hasil nilai signifikansi sebelum mendengarkan musik sebesar 0,103 dan sesudah mendengarkan musik sebesar 0,118. Maka dapatkan disimpulkan bahwa tidak mendengarkan musik dan mendengarkan musik data berdistribusi normal.

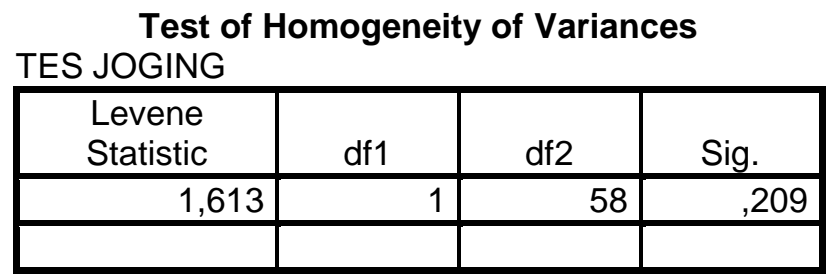

Berdasarkan tabel output diatas diketahui nilai signifikansi (Sig.) variabel Tes Joging adalah sebesar 0,209, oleh karena itu nilai Sig 0,209>0,05 maka sebagaimana dasar pengambilan keputusan dalam uji homogenitas diatas, dapat disimpulkan bahwa varians data Tes Joging adalah sama atau homogen.

Paired Samples Statistics

\begin{tabular}{|l|l|l|l|c|}
\hline & Mean & $\mathrm{N}$ & Std. Deviation & $\begin{array}{c}\text { Std. Error } \\
\text { Mean }\end{array}$ \\
\hline
\end{tabular}

Dipublikasikan Oleh :

UPT Publikasi dan Pengelolaan Jurnal

Universitas Islam Kalimantan Muhammad Arsyad Al-Banjari Banjarmasin 


\begin{tabular}{|r|r|r|r|r|}
\hline Pair 1 & TIDAK \\
MENDENGARKAN & 5,797 & 30 &, 8552 &, 1561 \\
$\begin{array}{l}\text { MUSIK } \\
\text { MENDENGARKAN } \\
\text { MUSIK }\end{array}$ & 6,527 & 30 & 1,1356 &, 2073 \\
\hline
\end{tabular}

Hasil statistik deskriptif dari kedua sampel yang diteliti yakni nilai Pre test (tidak mendengarkan musik) dan Post test (mendengarkan musik). Untuk nilai Pre test (tidak mendengarkan musik) diperoleh rata-rata hasil belajar atau Mean sebesar 5,797. Sedangkan untuk nilai Post test (mendengarkan musik) diperoleh nilai rata-rata hasil belajar sebesar 6,527. Jumlah responden atau atlet yang digunakan sebagai sampel penelitian adalah sebanyak 30 orang atlet. Untuk nilai Std. Deviation (standar deviasi) pada Pre Test (tidak mendengarkan musik) sebesar 0,8552 dan Post Test (mendengarkan musik) sebesar 1,1356. Terakhir adalah nilai Std. Error Mean untuk Pre test (tidak mendengarkan musik) sebesat 0,1561 dan untuk Post Test (mendengarkan musik) sebesar 0,2073.

Karena nilai rata-rata Tes joging pada Pre Test (tidak mendengarkan musik) 5,797 < Post Test (mendengarkan musik) 6,527, maka itu artinya secara deskriptif ada perbedaan rata-rata hasil belajar antara Pre Test (tidak mendengarkan musik) dengan Post Test (mendengarkan musik).

Paired Samples Test

\begin{tabular}{|c|c|c|c|c|c|c|c|c|c|}
\hline & & \multicolumn{5}{|c|}{ Paired Differences } & \multirow[b]{3}{*}{$\mathrm{t}$} & \multirow[b]{3}{*}{ df } & \multirow{3}{*}{$\begin{array}{l}\text { Sig. } \\
(2- \\
\text { taile } \\
\text { d) }\end{array}$} \\
\hline & & \multirow[b]{2}{*}{ Mean } & \multirow{2}{*}{$\begin{array}{c}\text { Std. } \\
\text { Deviatio } \\
n\end{array}$} & \multirow{2}{*}{$\begin{array}{l}\text { Std. } \\
\text { Error } \\
\text { Mean }\end{array}$} & \multicolumn{2}{|c|}{$\begin{array}{l}95 \% \text { Confidence } \\
\text { Interval of the } \\
\text { Difference }\end{array}$} & & & \\
\hline & & & & & Lower & Upper & & & \\
\hline $\begin{array}{l}\text { Pai } \\
\text { r } 1\end{array}$ & $\begin{array}{l}\text { TIDAK } \\
\text { MENDENGARKAN } \\
\text { MUSIK - } \\
\text { MENDENGARKAN } \\
\text { MUSIK }\end{array}$ &,- 7300 & 1,4106 & ,2575 & $-1,2567$ &,- 2033 & $\begin{array}{r}2,8 \\
35\end{array}$ & 29 & ,008 \\
\hline
\end{tabular}

Berdasarkan tsbel output "Pairec Sampel Test" di atas, diketahui nilai Sig. (2-tailed) adalah sebesar 0,008 < 0,05, maka H0 ditolak dan Ha diterima. Sehingga dapat disimpulkan bahwa ada perbedaan rata-rata antara Tes Joging Pre Test (tidak mendengarkan musik) dengan Post Test (mendengarkan musik) yang artinya ada perbandingan penggunaan musik saat joging dan tidak menggunakan musik saat joging terhadap hasil jarak tempuh joging.

\section{PENUTUP}

Berdasarkan analisis data dan pembahasan dapat disimpulkan bahwa ada perbandingan penggunaan musik saat joging dan tidak menggunakan musik saat joging terhadap hasil jarak tempuh joging, Berdasarkan tsbel output "Pairec Sampel Test" di atas, diketahui nilai Sig. (2-tailed) adalah sebesar 0,008 < 0,05, maka H0 ditolak dan Ha diterima.

Berdasarkan hasil penelitian tersebut, maka disampaikan beberapa saran sebagai usaha tindak lanjut sebagai berikut : (1) Kepada seluruh mahasiswa PJKR STKIP PGRI Lubuklinggau hendaklah senantiasa melakukan aktifitas joging sambil mendengarkan musik dalam meningkatkan jarak tempu joging tentu harapannya dapat meningkatkan kebugaran yang lebih baik lagi. (2) Bagi guru dan pembina olahraga hendaknya memberikan informasi kepada anak didiknya joging dengan mendengarkan musik lebih efektif dalam meningkatkan jarak tempuh. (3) Bagi peneliti selanjutnya, kiranya penelitian dapat dilanjutkan dengan permasalahan yang lebih luas lagi, sehingga dapat memberikan sumbangan pikiran kepada para pelatih, pembina olahraga maupun mahasisiswa agar dapat meningkatkan kebugaran.

Dipublikasikan Oleh : 


\section{REFERENSI}

Bateman \& Bale. 2009. Sporting Sounds : Relationship Between Sport and Music. New York : Routledge

Campbell, D. (2001). Efek Mozart, Memanfaatkan Kekuatan Musik Untuk Mempertajam Pikiran, Meningkatkan Kreativitas, Dan Menyehatkan Tubuh, Jakarta: Gramedia Pustaka Utama.

Chaplin, C.P. 1995. Kamus Lengkap Psikologi. Jakarta : PT Raja Grafindo Persada

Corbin, Charles B. dan Lindsey, Ruth. 1997. The Concepts of Physical Fitness With Laboratories, 9th Edition. Dubuque : Brown \& Benchmark

Dayat Suryana. (2012). Terapi Musik. http://books.google.co.id /books? $\mathrm{id}=$ fuCO5gqmoVcC\&printsec $=$ frontcover\&hl=id\&source=gbs_vpt_buy\# v=onepage\&q\&f=false diunduh pada tanggal 2 Januari 2017.

Deci, E. L., Ryan, R. M., \& Vansteenkiste, M. (2008). Self-determination theory and the explanatory role of psychological needs in human well-being dalam L. Bruni, F. Comim, \& M. Pugno (Eds.), Capabilities and happiness (pp. 187- 223). Oxford, UK: Oxford University Press

Deci, Edward \& Ryan, Richard M. 1985. Intrinsic Motivation and Self Determination in Human Behavior. New York : Plenum Press

Djohan. (2006). Terapi Musik (teori dan aplikasi). Yogyakarta: Galang Press.

Ferawati dan Siti Amiyakun. (2015). Pengaruh Pemberian Terapi Musik Terhadap Penurunan Kecemasan Dan Tingkat Stress Mahasiswa Semester VII Ilm Keperawatan Dalam Menghadapi Skirpsi Di Sekolah Tinggi Ilme Kesehatan Insane Cendekia Husada Bojonegoro. Bojoegoro: Stikes ICSADA. Jurnal Jumakia, Vol. 1 No. 1 Juni 2015.

Henderson. Joe, 2002. Cara Terbaik Olahraga Lari. Jakarta: PT RajaGrafindo Perseda.

Mahargyantari P. Dewi. (2009). Studi Metaanalisis: Musik Untuk Menurunkan Stres. Jurnal Psikologi. Vol. 36., No. 2

McGraw-Hill Education Mellalieu, S. D \& Hanton, S. (Ed.). 2009. Advanced in Applied Sport Psychology: A Review. New York : Routledge

Merrit, S. (2003). Simfoni Otak. Bandung: Kaifa

Nilsson, U. (2009). Caring Music : Music Intervention For Improved Health. (www.orebroll.se/uso/page_2436.aspx, diperoleh tanggal 2 Maret 2012).

Weng, Ting-Chun. 2006. Effect of Music-Listening on The Enjoyment of Physical Activity Experience. Chapel Hill : University of North Carolina

Dipublikasikan Oleh :

UPT Publikasi dan Pengelolaan Jurnal

Universitas Islam Kalimantan Muhammad Arsyad Al-Banjari Banjarmasin 